\title{
Impairment of circulating endothelial progenitors in Down syndrome
}

\author{
Valerio Costa ${ }^{1}$, Linda Sommese ${ }^{2}$, Amelia Casamassimi ${ }^{3}$, Roberta Colicchio ${ }^{4}$, Claudia Angelini ${ }^{5}$, \\ Valentina Marchesano ${ }^{6}$, Lara Milone ${ }^{7}$, Bartolomeo Farzati ${ }^{3}$, Alfonso Giovane ${ }^{7}$, Carmela Fiorito ${ }^{8}$, Monica Rienzo ${ }^{3}$, \\ Marco Picardii ${ }^{9}$ Bice Avallone ${ }^{6}$, Massimiliano Marco Corsi ${ }^{10}$, Berardo Sarubbi ${ }^{11}$, Raffaele Calabrò ${ }^{11}$, Paola Salvatore ${ }^{12}$, \\ Alfredo Ciccodicola ${ }^{{ }^{*}+}$, Claudio Napoli ${ }^{3+}$
}

\begin{abstract}
Background: Pathological angiogenesis represents a critical issue in the progression of many diseases. Down syndrome is postulated to be a systemic anti-angiogenesis disease model, possibly due to increased expression of anti-angiogenic regulators on chromosome 21 . The aim of our study was to elucidate some features of circulating endothelial progenitor cells in the context of this syndrome.
\end{abstract}

Methods: Circulating endothelial progenitors of Down syndrome affected individuals were isolated, in vitro cultured and analyzed by confocal and transmission electron microscopy. ELISA was performed to measure SDF-1 $\alpha$ plasma levels in Down syndrome and euploid individuals. Moreover, QRT-PCR was used to quantify expression levels of CXCL12 gene and of its receptor in progenitor cells. The functional impairment of Down progenitors was evaluated through their susceptibility to hydroperoxide-induced oxidative stress with BODIPY assay and the major vulnerability to the infection with human pathogens. The differential expression of crucial genes in Down progenitor cells was evaluated by microarray analysis.

Results: We detected a marked decrease of progenitors' number in young Down individuals compared to euploid, cell size increase and some major detrimental morphological changes. Moreover, Down syndrome patients also exhibited decreased SDF-1 $\alpha$ plasma levels and their progenitors had a reduced expression of SDF-1 $\alpha$ encoding gene and of its membrane receptor. We further demonstrated that their progenitor cells are more susceptible to hydroperoxide-induced oxidative stress and infection with Bartonella henselae. Further, we observed that most of the differentially expressed genes belong to angiogenesis, immune response and inflammation pathways, and that infected progenitors with trisomy 21 have a more pronounced perturbation of immune response genes than infected euploid cells.

Conclusions: Our data provide evidences for a reduced number and altered morphology of endothelial progenitor cells in Down syndrome, also showing the higher susceptibility to oxidative stress and to pathogen infection compared to euploid cells, thereby confirming the angiogenesis and immune response deficit observed in Down syndrome individuals.

\section{Background}

Down syndrome (DS) is a complex disorder caused by trisomy of the entire or a critical portion of chromosome 21 (HSA21); it represents the most frequent genetic cause of mental retardation, with a frequency of

\footnotetext{
* Correspondence: ciccodic@igb.cnr.it

+ Contributed equally

'Institute of Genetics and Biophysics "A. Buzzati-Traverso", IGB-CNR, Naples, Italy

Full list of author information is available at the end of the article
}

about 1/1000 new-borns, and is associated with a huge number of congenital heart defects [1]. DS individuals have also an increased risk of early-onset Alzheimer disease [1]. Immunological and autoimmune disturbances, with high rates of infections and malignancies, are recurrent phenomena in DS pathogenesis [2], and infections still represent major cause of death in DS $[3,4]$. Despite the increased risk of leukaemia, DS patients have a low incidence to develop solid tumors $[5,6]$, and
C Biomed Central

(C) 2010 Costa et al; licensee BioMed Central Ltd. This is an Open Access article distributed under the terms of the Creative Commons Attribution License (http://creativecommons.org/licenses/by/2.0), which permits unrestricted use, distribution, and reproduction in any medium, provided the original work is properly cited. 
a reduced incidence of diabetic retinopathy, suggesting, at least in part, a common angiogenesis' suppression $[5,7]$. Impaired endothelial function at a young age, possibly due to increased oxidative stress and yet unknown mechanisms, is a common DS feature [8].

DS phenotype results from a dosage imbalance of HSA21 genes, although expression analyses have reported conflicting results $[9,10]$. The over-expression of chromosome 21 genes greatly varies across the trisomic tissues $[11,12]$, and analyzing specific cell type/tissue, in easy-accessible and non-invasive manner, may be more productive [13,14].

Growing interest is emerging on circulating endothelial progenitor cells (EPCs) and their pivotal role in the maintenance of endothelium integrity, repair after injury and postnatal neovascularization [15-17]. Many studies are providing encouraging insights into the use of EPCs in the clinical setting $[18,19]$. Indeed, accumulating evidences indicate a reduced availability, and/or impaired EPC function, in cardiovascular and metabolic diseases $[17,20,21]$. EPCs number was recently shown to be impaired in DS fetuses and children [22,23] and CD34+ haematopoietic progenitors exhibited a marked growth decrease in Ts65Dn - a DS mouse model - accounting, at least in part, for DS vascular anomalies and defective immune response to pathogens [24].

Bacterial toxins may trigger pathogenic events through the over-production of cytokines and chemokines, leading to the alteration of endothelial function and capillary leakage [25]. Particularly, we recently demonstrated [26] that Bartonella henselae, a gram-negative intracellular bacteria responsible of vasoproliferative disorders in immunocompromised individuals $[27,28]$, adheres to and invades EPCs.

The present study was designed to pursue the molecular mechanisms contributing to immune, vascular and haematopoietic defective DS phenotypes, by investigating the number and functions of DS EPCs compared to euploid cells, also focusing on bioinformatics analysis of differentially expressed genes. Moreover, by using the previously described $B$. henselae model, we investigated the susceptibility of DS progenitors to this pathogen infection, also performing a detailed analysis of deregulated genes after Bartonella infection, with particular attention to angiogenesis and immune response pathways.

\section{Methods \\ Subjects}

DS and euploid donors were recruited at the Institute of General Pathology, Section of Clinical Pathology, Faculty of Medicine, University of Milan, and at the Second University of Naples, and an approval statement was obtained by the ethics' review boards of both Institutions. Informed consent was obtained from all persons involved in all clinical investigation of this study according to the principles expressed in the Declaration of Helsinki.

All subjects recruited for EPC isolation were free of infection, and no individual was taking any medication known to affect immune system/response. DS and euploid individuals were $65 \%$ males and $35 \%$ females as gender and $28 \pm 9$ as mean age. The experiments, where not specified, were performed on at least six DS and age-matched euploid individuals.

Plasma samples were obtained from 50 DS individuals and 30 age matched euploids subdivided into three age subgroups (young 0-20 y.o.; adult 21-40 y.o.; old 41-60 y.o.) as described elsewhere [29].

\section{EPC Isolation}

EPCs were isolated from non-institutionalized individuals with DS and age-matched euploid donors.

EPCs were isolated as previously described [30]. Briefly, PBMCs were isolated by density gradient centrifugation of peripheral blood samples on Histopaque1077 (Sigma). Cells were washed twice with PBS and counted. PBMCs were plated on culture dishes precoated with gelatin and fibronectin and maintained in endothelial basal medium-2 (EBM2; Cell Systems). Cells were cultured at $37^{\circ} \mathrm{C}$ with $5 \% \mathrm{CO} 2$ in a humidified atmosphere. After four days, non-adherent cells were removed and adherent cells were used for further analyses.

\section{Bacterial strains and growth conditions}

The B. henselae strain ATCC 49882 (LGC Promochem) was grown on Columbia agar supplemented with $5 \%$ defibrinated sheep blood (Oxoid) in a humidified atmosphere at $37^{\circ} \mathrm{C}$ and $5 \% \mathrm{CO} 2$. For production of bacterial stock suspensions, bacteria were harvested after 7 days of culture until they reached the mid-exponential phase of growth (109 bacteria/ml), resuspended in Tryptone Soya Broth USP (Oxoid) containing 10\% glycerol, and stored at $-80^{\circ} \mathrm{C}$. The number of viable bacteria in the frozen stocks was determined as previously described [26].

\section{B. henselae infection}

For infection, Bartonella stock solutions were thawed, washed and suspended in antibiotic-free cell culture medium, and sedimented onto cultured EPCs at different multiplicity of infection (MOI) of 50, 100, 250, 500 and 1000 [26]. The MOI for infections was confirmed by plating serial dilutions of the infection inoculum. Assays were performed three times in triplicate.

\section{Confocal immunofluorescence microscopy}

EPCs were dual stained with Dil-Ac-LDL and lectin from Ulex europaeus and counted both by fluorescence 
microscopy and flow cytometry as previously described $[26,30]$. Images were obtained by Zeiss LSM 510 with plan-apochromat X 63 (NA 1.4) oil immersion objective. EPCs images were used to measure cell size with ImageJ (http://rsb.info.nih.gov/ij/).

\section{SDF-1 $\alpha$ plasma levels}

Commercially available SDF-1 $\alpha$ ELISA kit (Quantikine, R\&D Systems) was used to determine plasma SDF- $1 \alpha$ levels. Tests were carried out at RT on freshly thawed plasma samples of 50 DS individuals and 30 age matched euploids subdivided into three age subgroups (young 0-20 y.o.; adult 21-40 y.o.; old 41-60 y.o.) [29]. Concentration was determined by comparison with a standard curve, following manufacturer's instruction.

\section{Transmission electron microscopy}

After a short incubation with Trypsin/EDTA, DS and euploid EPCs, both infected and uninfected with $B$. henselae, were harvested, centrifuged and washed in PBS. After centrifugation at a speed of $400 \mathrm{~g}$ for $7 \mathrm{~min}$, cells were fixed in $4 \%$ glutaraldehyde as described [31]. Postfixation, dehydratation of specimen, semithin $(2 \mu \mathrm{m})$ and ultrathin $(80 \mathrm{~nm})$ sections were performed as previously described [26]. Semithin sections were analysed with a light microscope (Polivar Reichert-Jung). Ultrathin sections were examined with Leo $912 \mathrm{AB}$ transmission electron microscope operating at $80 \mathrm{kV}$.

\section{C11-BODIPY581/591 fluorescence}

Oxidation-sensitive fluorescent probe, C11-BODIPY581/ 591 (C11-BO, Invitrogen), was loaded ( $2 \mu \mathrm{M}$ final concentration) into the cells $30 \mathrm{~min}$. before oxidative treatment. The samples were aliquoted in triplicate wells of a 24-well microplate, and fluorescence was determined with confocal laser microscopy at different times $(0,1$, and 6 hours) from oxidant treatment. Between times, plates were maintained at $37^{\circ} \mathrm{C}$ in $5 \% \mathrm{CO} 2$. To determine red fluorescence each microplate was excited at $543 \mathrm{~nm}$ (emission at $590 \mathrm{~nm}$ ); for green fluorescence, microplates were excited at $488 \mathrm{~nm}$ (emission at $526 \mathrm{~nm}$ ). Blank wells were also evaluated as well as $\mathrm{C} 11-\mathrm{BO}$ alone.

\section{Microarray analysis and quantitative RT-PCR}

Total RNA $(10 \mu \mathrm{g})$ was isolated as previously described [32] [Additional file 1: Supplementary Methods]. A pool of three samples (a total $15 \mu \mathrm{g}$ of cRNA) was used for each hybridization - 2 pools of three infected and three uninfected euploid and DS - on the Affymetrix U133 2.0 probe array cartridge as described elsewhere [26]. Microarray data were submitted to Array Express (http://www.ebi.ac.uk/arrayexpress; provisional accession number E-MTAB-312). Results were validated by qRTPCR and semi-qRT-PCR, performed as described [32], using primer pairs listed in [Additional file 2: Supplemental Table S1].

\section{In silico significant pathway identification}

Analysis of over-represented genes was performed using the Database for Annotation, Visualization, and Integrated Discovery (DAVID) $[33,34]$ and the PANTHER (Protein ANalysis THrough Evolutionary Relationships) Classification System [35 [Additional file 1: Supplementary Methods].

\section{Statistical analysis}

EPCs number, cell size differences, SDF- $1 \alpha$ plasma levels, fluorescence intensity of C11-BO and qRT-PCRs data were reported as mean values, and results analysed by paired Student $\mathrm{t}$ test. $P$ value $<0.05$ was considered statistically significant [Additional file 1: Supplementary Methods].

\section{Results}

\section{EPC number and phenotype}

We established that the number of EPCs isolated from peripheral blood of young and adult (mean age $28 \pm 9$ ) DS was significantly lower than age-matched euploid individuals $(P<0.0001$ vs euploid EPCs; see Figure 1A). Phase contrast fluorescent microscopy [Additional file 3: Supplemental Figure S1A] and FACS analysis (data not shown) were used to identify double-positive cells for Dil-Ac-LDL and lectin [26,30]. By confocal microscopy and TEM we also observed early signs of cytoplasmatic disruption in DS progenitors, and cell size increase compared to euploid. In particular, by using ImageJ, we measured the cell size of DS EPCs, showing a significant increase compared to euploid cells (Figures 1B and Additional file 3: Supplemental Figure S1B]). We also measured cell cycle progression of DS progenitors vs euploid cells and we did not find any significant difference [Additional file 3: Supplemental Figure S1C]. Moreover, the ultrastructural examination revealed an increased number of phagolysosomes and vacuolization of DS progenitors compared to euploid cells (Figure 1C).

\section{SDF- $1 \alpha$ plasma levels}

EPC number is known to correlate to chemokines' plasma levels, such as SDF- $1 \alpha$ (stromal derived factor- $1 \alpha$ ). Thus, we first measured by ELISA its plasma levels in peripheral blood of 30 euploid and 50 DS individuals, collected in three age subgroups [29]. Then, comparing mean SDF- $1 \alpha$ values we found a significant decrease of SDF-1 $\alpha$ plasma levels in young and adults DS compared to age-matched euploid individuals $(P=0.02)$ (Figure 1D).

Moreover, we measured by quantitative RT-PCR the expression of $S D F-1 \alpha$ encoding gene, $C X C L 12$, and of its membrane receptor $C X C R 4$. A significant decrease in the expression of CXCL12 (5-fold; $P<0.05$ ) and CXCR4 


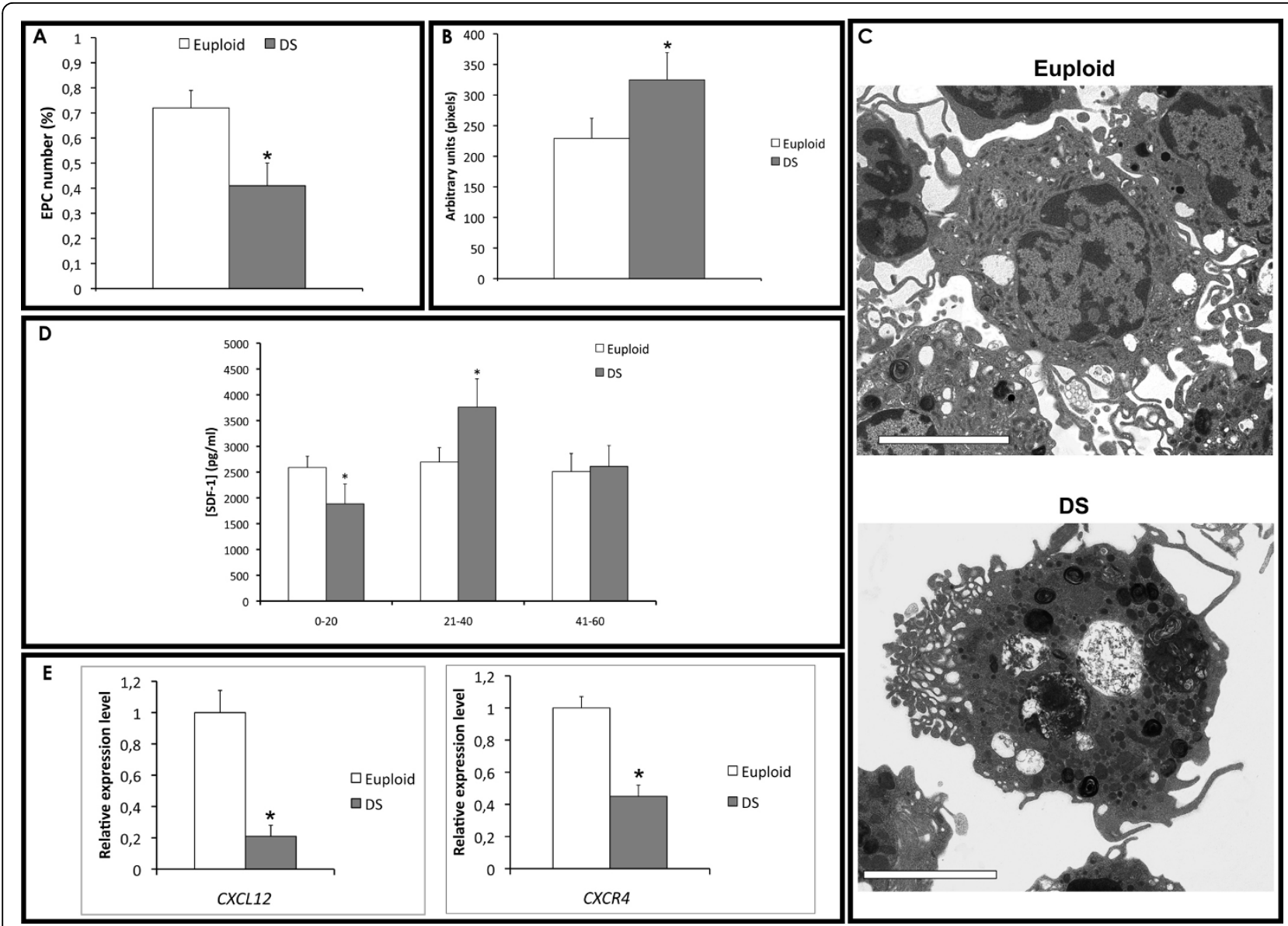

Figure 1 EPC number, mobilization and morphology in DS. A) EPCS number in euploids and DS determided as Dil-Ac-LDL/Lectin double positive cells ( $\left.{ }^{*} P<.0001\right)$. B) EPC size measured by confocal microscopy and ImageJ (*P < .0001). C) Morphological characterization by TEM of EPCs isolated from euploids and DS. Scale bar: $5 \mathrm{im}$. D) SDF- $1 \alpha$ plasma levels in DS and euploids $\left({ }^{*} P<.0001\right)$. E) Relative expression levels of CXCL12 and CXCR4 genes in euploids and DS measured by qRT-PCR $(* P<0.05)$.

(2-fold; $P<0.05)$ was observed in DS endothelial progenitors compared to euploid cells (Figure 1E).

\section{B. henselae infection of endothelial progenitors}

EPCs isolated from young euploid and DS individuals were infected after 3 days of culture with $B$. henselae at different MOI as described elsewhere [26] (Figure 2A). TEM examination confirmed that $B$. henselae is internalized by endothelial cells as bacterial aggregates within invasomes or as single bacteria by protrusions of the cells. Interestingly, the EPC number was dramatically impaired in both DS and euploid after bacteria internalization [Additional file 3: Supplemental Figure S1D]. In contrast, by confocal microscopy at high magnifications (x630), a more detrimental effect was observed in infected DS progenitors, showing some morphological major differences compared to euploid EPCs when the same non-lethal MOI of Bartonella was used (Figure 2A). Ultrastructural analysis revealed that infected DS progenitors have increased intracellular accumulation of bacteria, forming invasomes, compared to euploid cells infected at the same MOI of 100 (Figure 2B). Cytoplasmic protrusions of cell membranes were also observed in both samples following adherence of the bacteria to the host cells. Moreover, after infection at higher MOI (250), DS progenitors showed larger invasomes, also displaying, in some cases, invasome and cell membrane rupture with subsequent bacteria outflow (Figure 2B). In contrast, infected euploid cells showed significant lower number of invasomes. The number of infected DS cells was estimated to be significantly higher compared to euploid cells at both MOI used (Figure 2C). We did not use infection at MOI $\geq 500$ of $B$. henselae since they were not compatible with DS progenitors' survival.

\section{Oxidative stress in DS progenitors}

To determine oxidant activities in living cells, membrane lipid peroxidation (LP) of isolated EPCs was measured by using C11-BO, a fatty acid analogue. We cultured both DS and euploid EPCs in the presence of a 


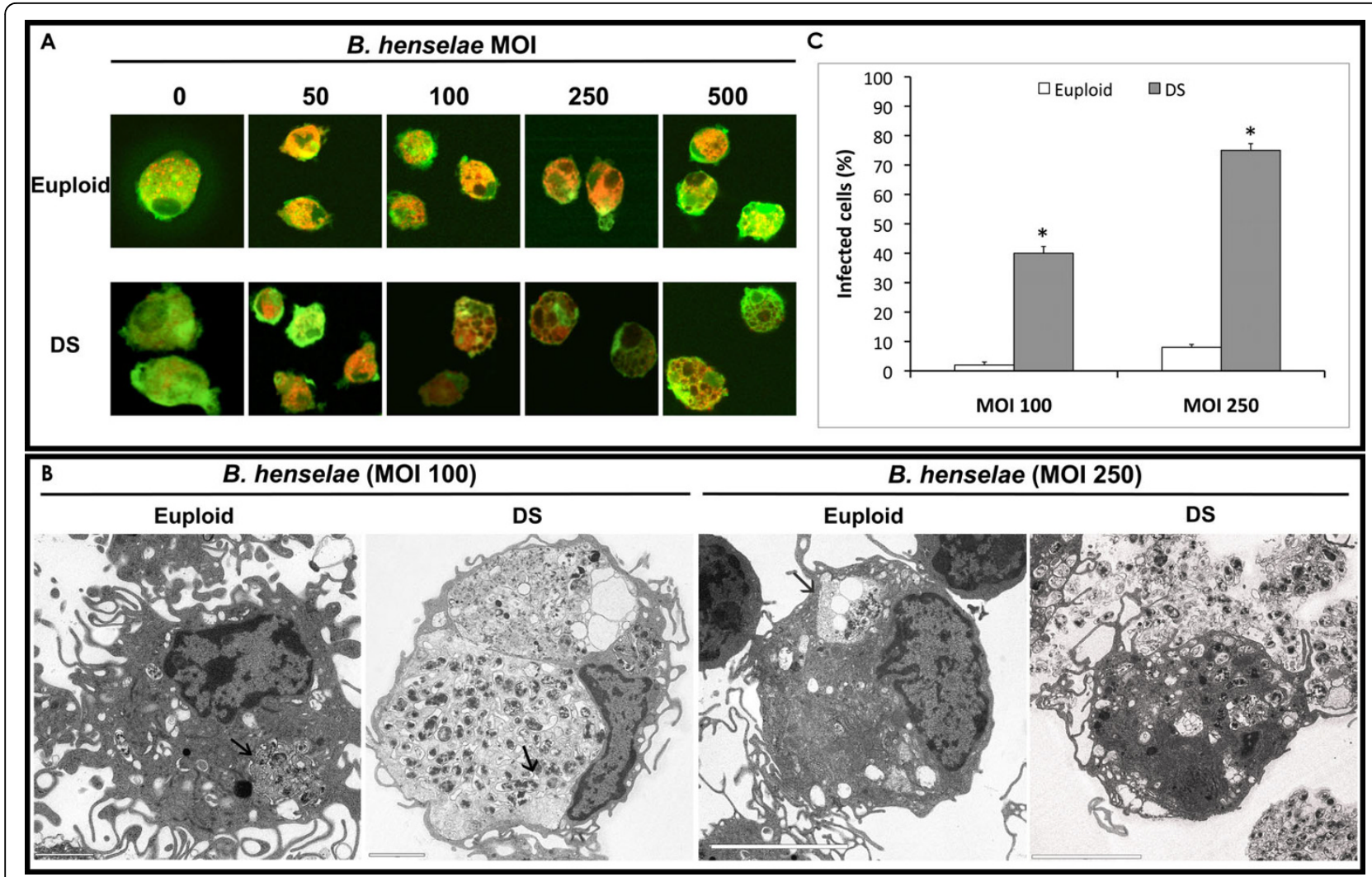

Figure 2 B. henselae infection. EPCS isolated from DS and euploids were infected at different $\mathrm{MOI}$ of Bartonella as indicated. A) Confocal images of uninfected and infected EPCs at indicated MOI. Cells were stained with Dil-Ac-LDL (red) and lectin (green). B) TEM images of DS and euploid EPCs infected at the MOI of 100 and 250. Invasomes are highlighted by arrows. Scale bars are $5 \mathrm{im}, 2 \mathrm{im}, 5 \mathrm{im}$ and 5 im, respectively. C) Bar graph representation of DS and euploid infected cells at different MOI.

fixed concentration of hydroperoxide (200 nM) [36], and performed a time-course ( 0,1 and 6 hours) experiment measuring the fluorescence emission by confocal microscopy. Particularly, in 6-hours treated DS samples, we observed a significant shift (Figure 3A upper panel) in the fluorescence emission from red towards green $(590 \mathrm{~nm}$ to $520 \mathrm{~nm}$ ) compared to untreated DS EPCs $(P<0.01)$. This shift was not observed in euploid hydroperoxide-treated EPCs vs untreated, as already described [36].

To evaluate the protective effects of $B$. henselae, known to induce - albeit at low MOI (50) - long-term endothelial cell survival and proliferation $[37,38]$, the same experiment was performed on DS and euploid progenitors infected with a low MOI (about 50) of Bartonella. No differences in LP were observed in both DS and euploid infected cells compared to uninfected, in the absence of hydroperoxide treatment (data not shown). More interestingly, a significant decrease in LP was observed in Bartonella-infected DS progenitors vs uninfected $(\mathrm{p}<0.01)$ (Figure 3A lower panel). This finding is in accordance to the previously reported beneficial effect of infection at low MOI of $B$. henselae $[37,38]$.
Moreover, it is known that a constitutive increase in $S 100 B$, due to HSA21 trisomy, is likely to induce ROS generation, leading to increased oxidative stress in DS [39], and the over-expression of SOD1 gene has been suggested to be responsible of oxidative damage to neurons [40]. Thus, we measured the expression levels of both $S 100 B$ and SOD1 genes in DS and euploid isolated EPCs, showing their significant over-expression in DS derived cells (Figure 3B).

\section{Chromosome 21 expression profile}

We chose a user fold-change of 2 and a P-value cut-off of 0.005 for selecting a list of differentially expressed genes, and we first focused on the HSA21 genes according to GenBank annotation. Thus, to evaluate the impact of an extra copy of chromosome 21 on DS progenitors we performed a detailed analysis of HSA21 genes in DS vs eupolid EPCs. We observed that only 109 out of a total of 386 genes annotated on HSA21 (NCBI RefSeq 36.3), were detected in this microarray analysis. Furthermore, 52 (about 14\% of total HSA21 annotated genes) showed an evidence of differential expression in DS EPCs compared to euploid cells. In 


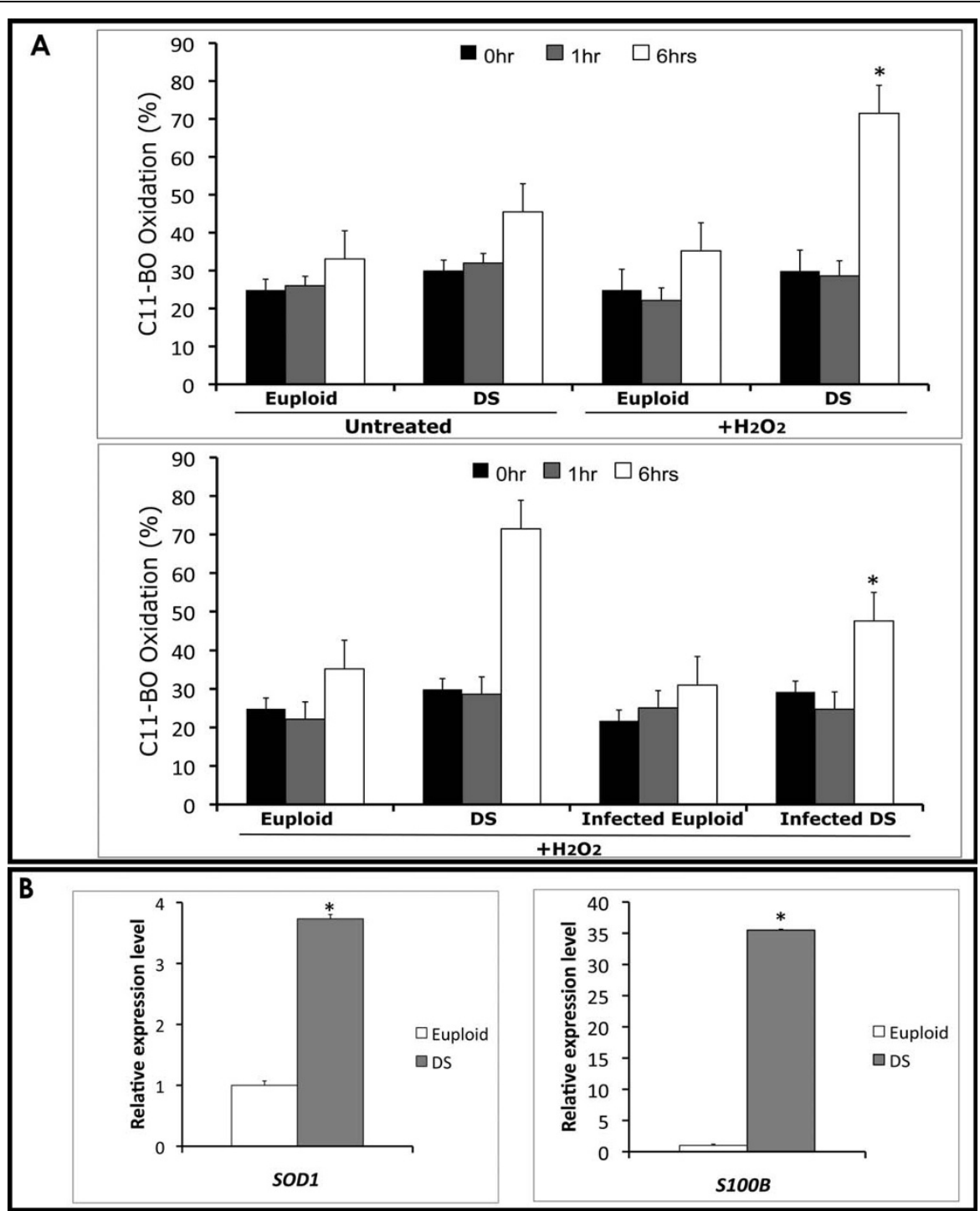

Figure 3 Oxidative stress of EPCs. A) Bar graph representation of C11-BO oxidation at different times (0, 1 and 6 hours) in DS and euploid EPCS in presence of hydroperoxide (200 iM). Upper panel, C11-BO oxidation in hydroperoxide-treated euploid EPCS compared to DS ( $\left.{ }^{*} P<0.01\right)$. Lower panel, Bartonella-infected euploid and DS progenitors treated and untreated with hydroperoxide $(* P<0.01)$. B) SOD1 and S100B gene expression in euploid and DS EPCS by qRT-PCR. Data are shown as relative expression levels (Euploid EPC expression $=1$ ).

particular, 37 genes were up- and 15 down-regulated (72\% up- and $28 \%$ down-regulated, respectively) [Additional file 4: Supplemental Table S2].

Database searches based on GO classification, revealed that differentially expressed genes were mostly associated to immune response (GO:0006955) and transcription regulation (GO:0045449) (Figure 4A). Particularly, crucial genes involved in the immune response, such as interferon receptors (IFNAR1 and IFNAR2), and oxidative stress, such as SOD1, S100B and APP - recently implicated in DS neurotoxicity from elevated expression of free radicals [39] - were highly up-regulated in DS vs euploid EPCs (Figure 3B; Additional file 4: Supplemental Table S2).
Although we observed relatively small up-regulation of chromosome 21 genes, significant changes in gene expression were not limited to HSA21 genes. Indeed, we observed a global and pronounced deregulation overall the chromosomes, possibly explained by dosage imbalance of HSA21 genes encoding transcriptional factors or gene expression modulators (Figure 4A; Additional file 4: Supplemental Table S2).

A less frequently explored gene characteristic for microarray analysis is the chromosomal location of the genes, especially when studying diseases caused by genome alterations. First we demonstrated, by using chisquared association tests, that differentially expressed 


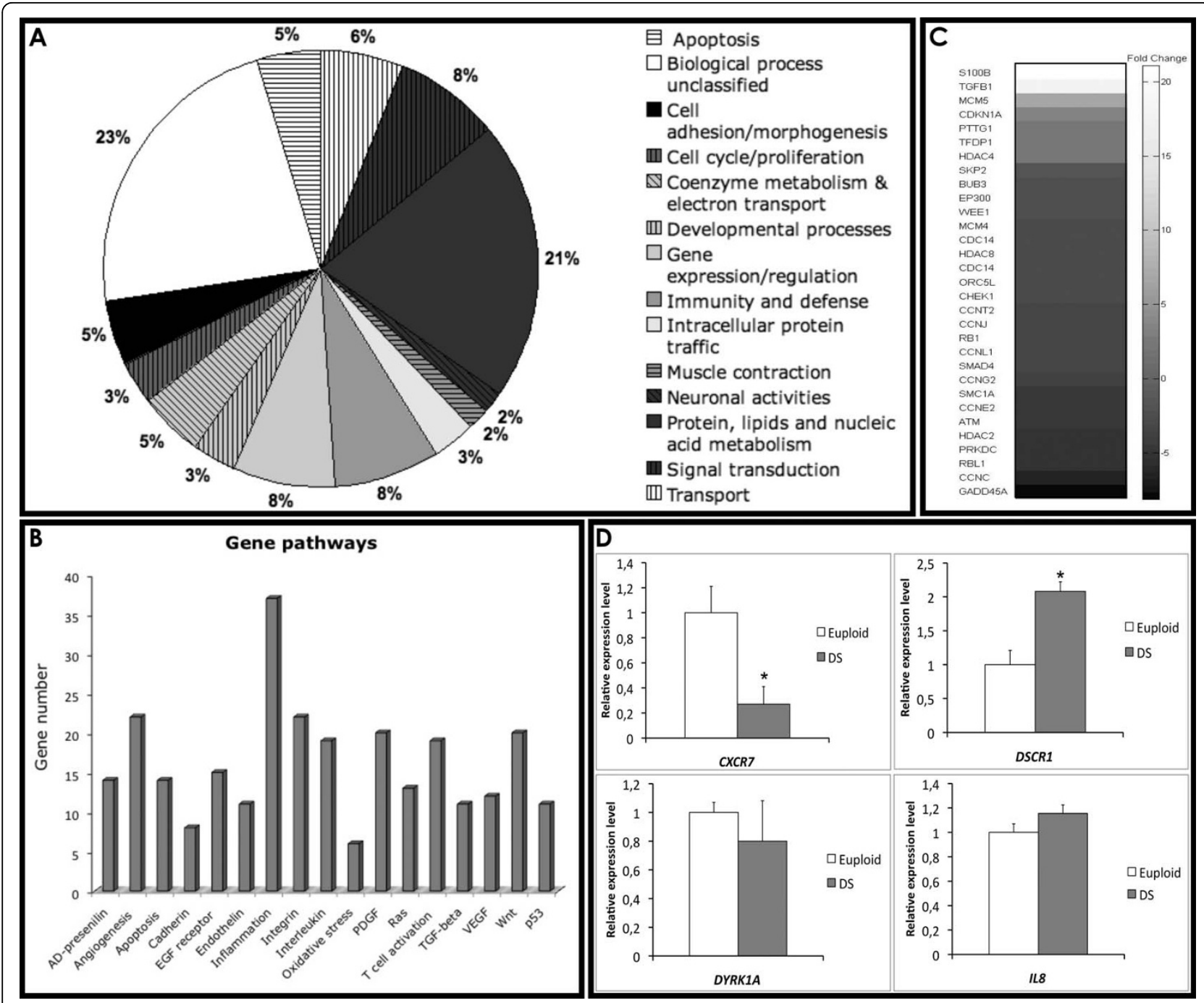

Figure 4 Differentially expressed genes in DS vs euploid progenitors. A) Schematic representation of chromosome 21 differentially expressed genes in DS vs euploid progenitors. Genes are categorized according to GO classification or their hypothetical biological function. B) Bar graph representation of more pronounced deregulated gene pathways in the whole genome of DS vs euploids, after PANTHER analysis. Vertical bars indicate the number of differentially expressed genes per pathway. C) HeatMap showing the fold-change of cell cycle and cell cycle-related differentially expressed genes in DS vs euploid progenitors. Gray intensity is proportional to the fold-change; the bar on the right illustrates the association between fold-changes and grayscale. The genes are ranked from the most up-regulated (white) to the most downregulated (black). D) qRT-PCR for crucial genes belonging to the most deregulated gene pathways are shown. Data are indicated as relative expression levels (Euploid EPCs $=1$ ).

genes are not uniformly distributed along the chromosomes. We observed that in DS EPCs the chromosomes 21 - as expected - and 19 were enriched for differentially expressed genes compared to the other chromosomes ( $\alpha$ 0.001; $P=6.7 \mathrm{E}-0.6$; Additional file 5: Supplemental Figure S2). As a proof of the robustness of our findings, the analysis was repeated with different fold-change and $P$ cut-offs, reporting similar qualitative findings. Moreover, by using positional gene enrichment (PGE) approach [41] to map a set of genes to the exact location on chromosome [Additional file 6: Supplemental Figure S3], we observed that chromosome 19 has the highest percent of deregulated genes [Additional file 3: Supplemental Figure S1A] and, in particular, that the enriched p12 band contains most of the genes encoding for transcription factors of the zinc finger protein superfamily.

\section{Gene pathways' perturbation in DS progenitors}

By using the same selection parameters, the comparison of global DS and euploid expression profiles revealed that, after filtering ("Materials and Methods"), 2913 genes (2489 of them with single probe and 424 with multiple probes) were differentially expressed, on a total 
of 11327 distinct genes considered. By using DAVID and PANTHER Classification System, differentially expressed genes were categorized according to their known or hypothetical biological function, and the enrichment for specific gene pathways was evaluated. The analysis revealed that most of the deregulated genes were involved in "angiogenesis", "inflammation mediated by cytokines and chemokines", "integrins" and "interleukines" signaling pathways (Figure 4B). A particular enrichment was also observed for cell cycle and cell cycle-related genes (Figure 4C).

Interestingly, angiogenesis inhibitors encoding genes such as CXCL1O and other interferon-stimulated genes were up-regulated in DS-derived progenitors, whereas, on the opposite, pro-angiogenic genes (VEGFA, $C X C L 12, E D N 1, C A S P 8)$ were dramatically down-regulated (Table 1).

Since evidences indicate that chemokines, cytokines and soluble factors affect the mobilization and recruitment of endothelial progenitors [42,43], we evaluated the expression of some crucial genes by quantitative RT-PCR (Figure 1E and 4D). Particularly, we observed a downregulation of CXCR4 receptor and of its ligand, encoded by $C X C L 12$ gene, in DS progenitors compared to euploid cells (Figure 1E), the over-expression of RCAN1 gene (or DSCR1) and the down-regulation of CXCR7 receptor (Figure 4D), which play a key role in endothelial cells migration and homing. No significant differential expression was observed for IL8 and DYRK1A genes in DS progenitors compared to euploid (Figure 4D).

\section{B. henseale-induced gene expression variations}

A similar approach for gene list selection was used to investigate the genetic response of DS-EPCs to $B$. henselae infection at a 100 MOI.

GO term enrichment analysis [38] showed that a considerable number of induced/repressed genes belong to immune and inflammatory response pathways [Additional file 7: Supplemental Figure S4], with the majority of genes annotated within the "Jak/STAT" and "Cytokine-cytokine receptor interaction" pathways. Furthermore, we categorized the most prominently up-regulated genes in DS infected EPCs in two related functional classes: "Interferons related/induced genes" and "cytokines and chemokines", consisting of 19 and 32 genes, respectively. The same approach was then used for infected euploid cells. Transcriptional levels of related genes, observed by microarray, are shown in [Additional file 8: Supplemental Table S3].

We focused our interest toward the cluster of differentially expressed genes of the Jak/STAT pathway (Figure 5). The analysis revealed that DS infected EPCs have a very distinct "molecular signature" compared to infected euploid progenitors, mostly characterized by the up-regulation of interferon-stimulated genes (ISGs). Particularly, a large subset of differentially expressed crucial genes was also confirmed by semi-quantitative RT-PCR [Additional file 7: Supplemental Figure S4]. As a reflection of the robust induction of ISGs, 'IFN signaling' was identified as the top scored pathway induced in DS progenitors after infection of $B$. henselae.

Other deregulated genes - involved in cell cycle regulation and gene expression - were further identified, many of which are known to be targets of interferon action as a consequence of the anti-proliferative effects.

\section{Discussion}

Alteration of EPC number has been described in a wide range of conditions, such as cardiovascular, inflammatory, immune, and infectious diseases [21,44]. A decreased in vitro growth capacity of bone marrowderived progenitors in DS mouse model Ts65Dn [24] and a reduced number of CD34+ in DS fetuses and children were also reported [22]. More recently, Diller

Table 1 Differential expression of angiogenesis-related genes in DS vs C endothelial progenitors

\begin{tabular}{ccccc}
\hline Gene name & Gene symbol & RefSeq & Fold change & Function \\
\hline Chemokine (C-X-C motif) ligand 10 & CXCL10 & NM_001565 & 6.7 I & Antiangiogenic chemokine \\
\hline $\begin{array}{c}\text { Interferon stimulated gene 20 } \\
\text { SAM domain- and HD domain- } \\
\text { containing protein 1 }\end{array}$ & SAMHD1 & NM_015474 & 3.0 I & Interferon- $\gamma$ stimulated; angiogenesis inhibitor \\
\hline Caspase 8 & CASP8 & NM_001228 & 3.5 D & Adhesion and homing of EPC \\
\hline Chemokine (C-X-C motif) ligand 12 & CXCL12 & NM_199168 & 10.2 D; 5.7 D & Mobilization and recruitment of EPCs \\
\hline Chemokine (C-X-C motif) receptor 4 & CXCR4 & NM_001008540 & 3.0 D & Endothelial cells migration and homing \\
\hline Chemokine (C-X-C motif) receptor 7 & CXCR7 & NM_020311 & 4.3 D & Endothelial cells migration and homing \\
\hline Endothelin 1 & EDN1 & NM_001955 & 13.6 D; 3.5 D & Promotes migration and proliferation of endothelial cells \\
\hline Endothelin receptor type B & EDNRB & NM_000115 & 2.8 D & Migration, proliferation of endothelial cells \\
\hline Vascular endothelial growth factor A & VEGFA & NM_001025367 & 3.6 D & Angioproliferative \\
\hline Stanniocalcin 1 & STC1 & NM_003155 & 56.0 D & VEGF-mediated angiogenic response \\
\hline
\end{tabular}




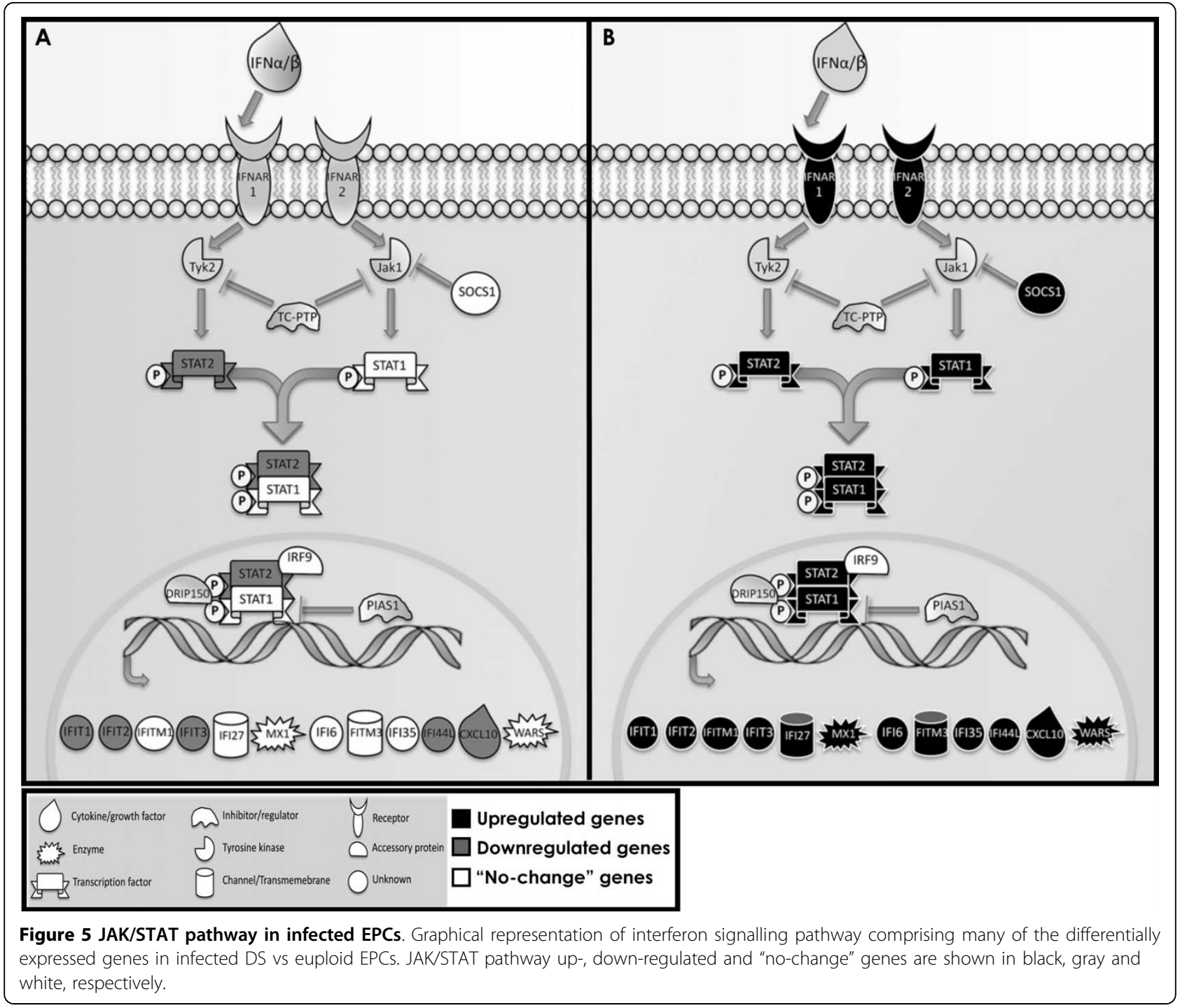

et al. (2008) reported an impairment of CD34+/AC133 $+/ \mathrm{KDR}+$ cells in a small subset of DS individuals affected by Eisenmenger syndrome [23]. Despite the use of different experimental approaches and the limited number of individuals, the reduced number of circulating progenitors is an important common finding. These evidences may possibly account for the differences in angiogenesis, inflammatory and immune response reported in DS [14].

Here, we have shown that DS patients exhibit a marked reduction of $\approx 40 \%$ in the number of EPCs, also displaying a significant increase in cell size and major detrimental morphological changes (i.e., cell vacuolization and high number of active lysosomes). The reduced number of progenitors could be associated with alterations in the cell cycle; however, we did not find any significant difference between the groups [Additional file 3 : Supplemental Figure S1C]. Thus, we investigated other possible mechanisms responsible for the observed EPCs impairment, such as mobilization/homing and oxidative stress susceptibility.

Growing evidences indicate that chemokines and cytokines, such as SDF- $1 \alpha$ and its receptor CXCR4, play a crucial role in the mobilization and homing of EPCs from bone marrow [45,46], also affecting cell proliferation $[41,42]$. Our findings of a significant decrease in SDF- $1 \alpha$ plasma levels in young DS - compared to agematched euploids - and a strong decrease of CXCL12 and CXCR4 gene transcription in their EPCs, suggest a link with the reduced number of circulating progenitors and the angiogenesis suppression observed in DS.

These results are strengthened by microarray analysis, indicating that DS progenitors have a pronounced perturbation, at least at transcriptional level, in the angiogenesis and cell cycle pathways. Indeed, by using this approach we demonstrated the transcriptional 
deregulation of CXCR7, IL8 and RCAN1 genes, crucial factors involved in endothelial cells' migration, homing and angiogenesis [47-49]. Moreover, we found a downregulation of CASP8, which has been demonstrated to have a novel apoptosis-unrelated role in proangiogenic cells [50], although this gene was found to be associated with breast cancer by gene-based association study, and its down-regulation has also been reported in breast cancer [51].

We recently demonstrated the relevance of oxidative stress on the number and function of progenitor cells [52]. Besides, it is known that oxidative stress is a crucial issue in the pathogenesis of DS, especially due to the high incidence of Alzheimer-like disease at young age [53]. It has been also suggested that constitutive expression of trisomic genes, $S 100 B$ and $S O D 1$, is likely to represent a leading cause of ROS generation and increased oxidation in DS neurons [39,40]. Oxidative stress relevance in DS fetuses was also highlighted by microarray analysis of uncultured amniotic fluid [54].

Here, we have assessed, by both experimental evidences and microarray analysis, that DS progenitors are more susceptible to hydroperoxide-induced LP and significantly over-express $S 100 B$ and SOD1 genes. These findings strengthen the hypothesis of their involvement in the susceptibility to oxidation observed in DS endothelial progenitors.

In our study we have infected DS progenitors with a human pathogen, $B$. henselae, responsible of vasoproliferative diseases such as bacillary angiomatosis and peliosis in immunocompromised patients $[27,28]$, previously demonstrated to adhere to and invade EPCs [26]. Particularly, we investigated the effect of infection on DS progenitors' number, morphology and oxidative stress response. After hydroperoxide treatment, we observed a significant LP decrease in Bartonella-infected DS progenitors compared to uninfected DS cells. This finding confirms the beneficial effect of $B$. henselae infection at low MOI on mature endothelial cells' survival $[37,38]$.

In contrast, a reduced cell number in both DS and euploid groups was observed after Bartonella infection at higher MOIs; however, detrimental changes were visible only in DS EPCs, displaying a higher number of invasomes and infected cells compared to euploid cells.

The molecular basis of such Bartonella-induced detrimental effect on endothelial progenitors of DS was investigated at a transcriptional level by microarray. Significant up-regulation of the Jak/STAT pathway was observed only within infected DS progenitors, whereas, on the opposite, infected euploid cells displayed a significant down-regulation. These findings strengthen the hypothesis that transcriptional analysis of EPCs is clearly of major interest in the context of this syndrome. Indeed, the activation of ISGs, involved in the immune response against infections and in tumor surveillance [55], also inhibits angiogenesis by decreasing the production of angiogenic factors such as VEGF and IL8 [56]. Our results clearly show that a similar ISGs activation occurs in infected DS progenitor cells, and, albeit at lower levels, in uninfected DS progenitors (data not shown).

Pathologic immune and inflammatory responses are regulated by the cross-talk between interferons and TNF $\alpha$ [26], as well as deregulation of chemokines/cytokines greatly affects the mobilization and recruitment of endothelial progenitors. The imbalance between ISGs and other molecules might be of great immunological relevance concerning the well-known DS haematological defects.

\section{Conclusions}

Physiological angiogenesis plays a central role in the embryogenesis and placental development; on the other hand, pathological angiogenesis represents a critical issue in the progression of many diseases, such as solid tumor growth and retinopathy.

Individuals with Down syndrome, due to decreased incidence of angiogenesis-dependent diseases, have been postulated to be a systemic anti-angiogenesis model. Indeed, they exhibit a significantly increased anti-angiogenic surveillance, possibly due to increased expression of anti-angiogenic regulators on chromosome 21 [57].

However, it has been shown a complex regulation of gene expression not only related to gene copy number, with several genes escaping the rule of "increased transcription proportional to the gene copy number" $[58,59]$. This findings suggest that many pathological traits observed in DS may be controlled by other more complex and, above all tissue-specific, regulatory mechanisms [59].

Our study shows that circulating endothelial progenitors are reduced in patients with DS, possibly correlating to the low SDF-1 $\alpha$ plasma levels, to a reduced expression of its membrane receptor in these cells, and to their higher oxidative stress and pathogen infection susceptibility compared to euploid cells. A significant perturbation in the angiogenesis and inflammation gene pathways was also observed by microarray analysis, highlighting that gene expression analysis is a crucial issue for the study of common diseases. Endothelial dysfunction, angiogenesis' suppression and infection recurrence are hallmarks of DS, and the impairment in the number and function of circulating progenitors may account for some of their pathological features. Further studies are needed to understand possible therapeutic implications of circulating EPCs in Down syndrome. 


\section{Additional material}

\section{Additional file 1: Supplementary Methods \\ Additional file 2: Table S1: Primer pairs used for quantitative and semi-quantitative RT-PCR}

Additional file 3: Figure S1: Impaired EPC number and function. A) Representative photomicrographs of merged double-positive Dil-Ac-LDL/ Lectin cells isolated from euploid (left panel) and DS (right panel) subjects (100X magnification). B) Fluorescence micrographs of EPCs labeled for 30 min with C11-BO in euploid and DS subjects. C) EPC number expressed as percentage in the different phases of cell cycle obtained by FACS. D) Curves indicate the percentage of EPC number infected with $B$. henselae in euploid and DS individuals. Results are representative of five different experiments in duplicate.

Additional file 4: Table S2: Chromosome 21 genes differentially expressed in DS vs euploids

Additional file 5: Figure S2: Distribution of differentially expressed genes along the human chromosomes (DS vs euploids). A) Bar graph showing the empirical frequency distribution of differentially expressed genes along the autosomes of DS progenitors vs euploids. Asterisks indicate the significantly deregulated chromosomes. B) Representation of the robustness of our findings shown in A. The left column shows the different user-defined fold-change. For each á value used in the analysis are shown the relative p-values. C) Bar graph showing the percent of differentially expressed genes along the DS autosomes.

\section{Additional file 6: Figure S3: Positional gene mapping of} differentially expressed genes (DS vs euploids). Graphic representation of positional gene enrichment (PGE) approach used to map differentially expressed genes in DS vs euploids EPCs to the exact location on the chromosome.

Additional file 7: Figure S4: $B$. henseale-induced gene expression in DS EPCs. A) Bar graph showing the top-scored deregulated gene pathways after infection in DS progenitors. Ratio indicates the percent of differentially expressed genes within the related pathway. B) Semiquantitative RT-PCR of Jak/STAT genes deregulated after $B$. henseale infection.

Additional file 8: Table S3: Differentially expressed genes after $B$. henselae infection

\section{Acknowledgements}

We thank the patients and individuals recruited as controls for their participation. This work was supported by Legge 5, Regione Campania 2008 to Prof. A. Ciccodicola; PRIN 2006, Foundation Jerome Lejeune, and Regione Campania 2008 to Prof. C. Napoli; and Progetto di Rilevante Interesse Nazionale Ministero Italiano Università e Ricerca 2006 [grant number 2006068944_001] "Basi genetiche e molecolari della patogenicità batterica" to Prof. P. Salvatore.

\section{Author details}

"Institute of Genetics and Biophysics "A. Buzzati-Traverso", IGB-CNR, Naples, Italy. ${ }^{2}$ Section of Microbiology, Department of Experimental Medicine, 1st School of Medicine, Second University of Naples, Naples, Italy. ${ }^{3}$ Department of General Pathology and Excellence Research Center on Cardiovascular Diseases, 1st School of Medicine, Second University of Naples, Naples, Italy. ${ }^{4}$ IRCCS Fondazione SDN, Naples, Italy. ${ }^{5}$ Istituto per le Applicazioni del Calcolo, "Mauro Picone", CNR, Naples, Italy. ${ }^{6}$ Department of Biological Science, University of Naples "Federico II", Naples, Italy. 'Department of Biochemistry and Biophysics, Second University of Naples, Naples, Italy. ${ }^{8}$ IRCCS Multimedica, Milan, Italy. ${ }^{9}$ Department of Biochemistry and Medical Biotechnology, University of Naples "Federico II", Naples, Italy. ${ }^{10}$ Institute of General Pathology, Section of Clinical Pathology, Faculty of Medicine, University of Milan, Milan, Italy. ${ }^{11}$ Cardiology Department of Second University of Naples, "Monaldi Hospital", Naples, Italy. ${ }^{12}$ Department of Cellular and Molecular Biology and Pathology "L. Califano" and School of Biotechnological Sciences, University of Naples "Federico II", Naples, Italy.

\section{Authors' contributions}

$C V, L S, A C a, B A, P S, A C i$ and CN designed research. CV, LS, ACa, RCo, VM, LM CF, MR and MP carried out experimental research. VM and BA performed Transmission electron microscopy. CV and MR performed microarray analysis and quantitative RT-PCR. CV and CAn assisted with statistical analysis. BF, $M M C, B S$ and $R C a$ participated in the participant recruitment. CV, LS, ACa, $R C o, C A n, V M, L M, B F, A G, C F, M R, M P, B A, M M C, B S, R C a, P S, A C i$ and $C N$ analyzed data. CV, LS, ACa, CAn, BA, PS, ACi and CN wrote the paper. All authors read and approved the final manuscript.

\section{Competing interests}

The authors declare that they have no competing interests.

Received: 17 February 2010 Accepted: 13 September 2010 Published: 13 September 2010

\section{References}

1. Wiseman FK, Alford KA, Tybulewicz VL, Fisher EM: Down syndrome-recent progress and future prospects. Hum Mol Genet 2009, 18:75-83.

2. Gillespie KM, Dix RJ, Williams AJ, Newton R, Robinson ZF, Bingley PJ, Gale EA, Shield JP: Islet autoimmunity in children with Down's syndrome. Diabetes 2006, 55:3185-3188.

3. Ugazio AG, Maccario R, Notarangelo LD, Burgio GR: Immunology of Down syndrome: a review. Am J Med Genet Suppl 1990, 7:204-212.

4. Garrison MM, Jeffries $H$, Christakis DA: Risk of death for children with down syndrome and sepsis. J Pediatr 2005, 147:748-752

5. Folkman J: Angiogenesis: an organizing principle for drug discovery? Nat Rev Drug Discov 2007, 6:273-286.

6. Hasle $\mathrm{H}$, Clemmensen $\mathrm{H}$, Mikkelsen M: Risks of leukaemia and solid tumours in individuals with Down's syndrome. Lancet 2000, 355:165-169.

7. Fulcher T, Griffin M, Crowley S, Firth R, Acheson R, O' Meara N: Diabetic retinopathy in Down's syndrome. Br J Ophthalmol 1998, 82:407-409.

8. Cappelli-Bigazzi M, Santoro G, Battaglia C, Palladino MT, Carrozza M, Russo MG, Pacileo G, Calabrò R: Endothelial cell function in patients with Down's syndrome. Am J Cardiol 2004, 94:392-395.

9. FitzPatrick DR, Ramsay J, McGill NI, Shade M, Carothers AD, Hastie ND: Transcriptome analysis of human autosomal trisomy. Hum Mol Genet 2002, 11:3249-3256.

10. Mao R, Zielke CL, Zielke HR, Pevsner J: Global up-regulation of chromosome 21 gene expression in the developing Down syndrome brain. Genomics 2003, 81:457-467.

11. Li CM, Guo M, Salas M, Schupf N, Silverman W, Zigman WB, Husain S, Warburton D, Thaker H, Tycko B: Cell type-specific over-expression of chromosome 21 genes in fibroblasts and fetal hearts with trisomy 21. BMC Med Genet 2006, 7:24.

12. Sommer CA, Pavarino-Bertelli EC, Goloni-Bertollo EM, Henrique-Silva F: Identification of dysregulated genes in lymphocytes from children with Down syndrome. Genome 2008, 51:19-29.

13. Gardiner K: Gene-dosage effects in Down syndrome and trisomic mouse models. Genome Biol 2004, 5:244.

14. Antonarakis SE, Epstein CJ: The challenge of Down syndrome. Trends Mol Med 2006, 12:473-479.

15. Yoder MC, Mead LE, Prater D, Krier TR, Mroueh KN, Li F, Krasich R, Temm CJ, Prchal JT, Ingram DA: Redefining endothelial progenitor cells via clonal analysis and hematopoietic stem/progenitor cell principals. Blood 2007, 109:1801-1809.

16. Hirschi KK, Ingram DA, Yoder MC: Assessing identity, phenotype, and fate of endothelial progenitor cells. Arterioscler Thromb Vasc Biol 2008, 28:1584-1595.

17. Zampetaki A, Kirton JP, Xu Q: Vascular Repair by Endothelial Progenitor Cells. Cardiovascular Research 2008, 78:413-421

18. Krenning G, van Luyn MJ, Harmsen MC: Endothelial progenitor cell-based neovascularization: implications for therapy. Trends Mol Med 2009, 15:180-189.

19. Shantsila E, Watson T, Lip GY: Endothelial progenitor cells in cardiovascular disorders. Journal of the American College of Cardiology 2007, 49:741-752.

20. Vasa M, Fichtlscherer S, Aicher A, Adler K, Urbich C, Martin H, Zeiher AM, Dimmeler S: Number and migratory activity of circulating andothelial progenitor cells inversely correlate with risk factors for coronary artery disease. Circulation Research 2001, 89:e1-7. 
21. Sabatier F, Camoin-Jau L, Anfosso F, Sampol J, Dignat-George F: Circulating endothelial cells, microparticles and progenitors: key players towards the definition of vascular competence. J Cell Mol Med 2009, 13:454-471.

22. Holmes DK, Bates N, Murray M, Ladusans EJ, Morabito A, Bolton-Maggs PH, Johnston TA, Walkenshaw S, Wynn RF, Bellantuono I: Hematopoietic progenitor cell deficiency in fetuses and children affected by Down's syndrome. Exp Hematol 2006, 34:1611-1615.

23. Diller GP, van Eijl S, Okonko DO, Howard LS, Ali O, Thum T, Wort SJ, Bédard E, Gibbs JS, Bauersachs J, Hobbs AJ, Wilkins MR, Gatzoulis MA, Wharton J: Circulating endothelial progenitor cells in patients with Eisenmenger syndrome and idiopathic pulmonary arterial hypertension. Circulation 2008, 117:3020-3030

24. Jablonska B, Ford D, Trisler D, Pessac B: The growth capacity of bone marrow CD34 positive cells in culture is drastically reduced in a murine model of Down syndrome. C R Biol 2006, 329:726-732.

25. Mantovani A, Sozzani S, Introna M: Endothelial activation by cytokines. Ann N Y Acad Sci 1997, 832:93-116.

26. Salvatore P, Casamassimi A, Sommese L, Fiorito C, Ciccodicola A, Rossiello R, Avallone B, Grimaldi V, Costa V, Rienzo M, Colicchio R, Williams-Ignarro S, Pagliarulo C, Prudente ME, Abbondanza C, Lamberti F, Baroni A, Buommino E, Farzati B, Tufano MA, Ignarro LJ, Napoli C: Detrimental effects of Bartonella henselae are counteracted by L-arginine and nitric oxide in human endothelial progenitor cells. Proc Natl Acad Sci USA 2008, 105:9427-9432.

27. Dehio C: Bartonella-host-cell interactions and vascular tumour formation. Nat Rev Microbiol 2005, 3:621-631.

28. Kunz S, Oberle K, Sander A, Bogdan C, Schleicher U: Lymphadenopathy in a novel mouse model of Bartonella-induced cat scratch disease results from lymphocyte immigration and proliferation and is regulated by interferon-alpha/beta. Am J Pathol 2008, 172:1005-1018,

29. Dogliotti G, Galliera E, Licastro F, Corsi MM: Age-related changes in plasma levels of BDNF in Down syndrome patients. Immun Ageing 2010, 7:2.

30. Casamassimi A, Balestrieri ML, Fiorito C, Schiano C, Maione C, Rossiello R, Grimaldi V, Del Giudice V, Balestrieri C, Farzati B, Sica V, Napoli C: Comparison between total endothelial progenitor cell isolation versus enriched CD133+ culture. J Biochem 2007, 141:503-511.

31. Avallone B, Porritiello M, Esposito D, Mutone R, Balsamo G, Marmo F: Evidence for hair cell regeneration in the crista ampullaris of the lizard Podarcis sicula. Hear Res 2003, 178:79-88.

32. Costa V, Conte I, Ziviello C, Casamassimi A, Alfano G, Banfi S, Ciccodicola A: Identification and expression analysis of novel Jakmip1 transcripts. Gene 2007, 402:1-8

33. Hosack DA, Dennis G Jr, Sherman BT, Lane HC, Lempicki RA: Identifying biological themes within lists of genes with EASE. Genome Biol 2003, 4: R70.

34. Huang da W, Sherman BT, Lempicki RA: Systematic and integrative analysis of large gene lists using DAVID bioinformatics resources. Nat Protoc 2009, 4:44-57.

35. Thomas PD, Campbell MJ, Kejariwal A, Mi H, Karlak B, Daverman R, Diemer K, Muruganujan A, Narechania A: PANTHER: a library of protein families and subfamilies indexed by function. Genome Res 2003 13:2129-2141.

36. Dernbach E, Urbich C, Brandes RP, Hofmann WK, Zeiher AM, Dimmller S: Antioxidative stress-associated genes in circulating progenitor cells: evidence for enhanced resistance against oxidative stress. Blood 2004, 104:3591-3597.

37. Kirby JE, Nekorchuk DM: Bartonella-associated endothelial proliferation depends on inhibition of apoptosis. Proc Natl Acad Sci USA 2002, 99:4656-4661.

38. Pulliainen AT, Dehio C: Bartonella henselae: subversion of vascular endothelial cell functions by translocated bacterial effector proteins. Int $J$ Biochem Cell Biol 2009, 41:507-510.

39. Esposito G, Imitola J, Lu J, De Filippis D, Scuderi C, Ganesh VS, Folkerth R, Hecht J, Shin S, luvone T, Chesnut J, Steardo L, Sheen V: Genomic and functional profiling of human Down syndrome neural progenitors implicates S100B and aquaporin 4 in cell injury. Hum Mol Genet 2008, 17:440-457.

40. Lee $M$, Hyun D, Jenner P, Halliwell B: Effect of overexpression of wild-type and mutant $\mathrm{Cu} / \mathrm{Zn}$-superoxide dismutases on oxidative damage and antioxidant defences: relevance to Down's syndrome and familial amyotrophic lateral sclerosis. J Neurochem 2001, 76:957-965.
41. De Preter K, Barriot R, Speleman F, Vandesompele J, Moreau Y: Positional gene enrichment analysis of gene sets for high-resolution identification of overrepresented chromosomal regions. Nucleic Acids Res 2008, 36:e43.

42. Hristov M, Wolfgang W, Weber PC: Endothelial progenitor cells mobilization differentiation and homing. Arterioscler Thromb Vasc Biol 2003, 23:1185-1189.

43. Egan CG, Lavery R, Caporali F, Fondelli C, Laghi-Pasini F, Dotta F, Sorrentino V: Generalised reduction of putative endothelial progenitors and CXCR4-positive peripheral blood cells in type 2 diabetes. Diabetologia 2008, 51:1296-1305.

44. Schmidt-Lucke C, Rössig L, Fichtlscherer S, Vasa M, Britten M, Kamper U, Dimmeler S, Zeiher AM: Reduced number of circulating endothelial progenitor cells predicts future cardiovascular events: proof of concept for the clinical importance of endogenous vascular repair. Circulation 2005, 111:2981-2987.

45. Yamaguchi J, Kusano KF, Masuo O, Kawamoto A, Silver M, Murasawa S, Bosch-Marce M, Masuda H, Losordo DW, Isner JM, Asahara T: Stromal cellderived factor-1 effects on ex vivo expanded endothelial progenitor cell recruitment for ischemic neovascularization. Circulation 2003, 107:1322-1328

46. Walter DH, Haendeler J, Reinhold J, Rochwalsky U, Seeger F, Honold J, Hoffmann J, Urbich C, Lehmann R, Arenzana-Seisdesdos F, Aicher A, Heeschen C, Fichtlscherer S, Zeiher AM, Dimmeler S: Impaired CXCR4 signaling contributes to the reduced neovascularisation capacity of endothelial progenitor cells from patients with coronary artery disease. Circ Res 2005, 97:1142-1151.

47. Waugh DJ, Wilson C: The interleukin-8 pathway in cancer. Clin Cancer Res 2008, 14:6735-6741.

48. Burns JM, Summers BC, Wang Y, Melikian A, Berahovich R, Miao Z, Penfold ME, Sunshine MJ, Littman DR, Kuo CJ, Wei K, McMaster BE, Wright K, Howard MC, Schall TJ: A novel chemokine receptor for SDF-1 and I-TAC involved in cell survival, cell adhesion, and tumor development. J Exp Med 2006, 203:2201-2213.

49. Baek KH, Zaslavsky A, Lynch RC, Britt C, Okada Y, Siarey RJ, Lensch MW, Park IH, Yoon SS, Minami T, Korenberg JR, Folkman J, Daley GQ, Aird WC, Galdzicki Z, Ryeom S: Down's syndrome suppression of tumour growth and the role of the calcineurin inhibitor DSCR1. Nature 2009, 459:1126-1130.

50. Scharner D, Rössig L, Carmona G, Chavakis E, Urbich C, Fischer A, Kang TB, Wallach D, Chiang YJ, Deribe YL, Dikic I, Zeiher AM, Dimmeler S: Caspase-8 is involved in neovascularization-promoting progenitor cell functions. Arterioscler Thromb Vasc Biol 2009, 29:571-578.

51. Wu Y, Alvarez M, Slamon DJ, Koeffler P, Vadgama JV: Caspase 8 and maspin are downregulated in breast cancer cells due to $\mathrm{CpG}$ site promoter methylation. BMC Cancer 2010, 10:32

52. Fiorito C, Rienzo M, Crimi E, Rossiello R, Balestrieri ML, Casamassimi A, Muto F, Grimaldi V, Giovane A, Farzati B, Mancini FP, Napoli C: Antioxidants increase number of progenitor endothelial cells through multiple gene expression pathways. Free Radic Res 2008, 42:754-762.

53. Zana M, Janka Z, Kálmán J: Oxidative stress: a bridge between Down's syndrome and Alzheimer's disease. Neurobiol Aging 2007, 28:648-676

54. Slonim DK, Koide K, Johnson KL, Tantravahi U, Cowan JM, Jarrah Z, Bianchi DW: Functional genomic analysis of amniotic fluid cell-free mRNA suggests that oxidative stress is significant in Down syndrome fetuses. Proc Natl Acad Sci USA 2009, 106:9425-9429.

55. Borden EC, Sen GC, Uze G, Silverman RH, Ransohoff RM, Foster GR, Stark GR: Interferons at age 50: past, current and future impact on biomedicine. Nat Rev Drug Discov 2007, 6:975-990.

56. Rosewicz S, Detjen K, Scholz A, von Marschall Z: Interferon-alpha: regulatory effects on cell cycle and angiogenesis. Neuroendocrinology 2004, 80:85-93.

57. Ryeom S, Folkman J: Role of Endogenous Angiogenesis Inhibitors in Down Syndrome. J Craniofac Surg 2009, 20:595-596.

58. Lyle R, Gehrig C, Neergaard-Henrichsen C, Deutsch S, Antonarakis SE: Gene expression from the aneuploid chromosome in a trisomy mouse model of down syndrome. Genome Res 2004, 14:1268-1274.

59. Kahlem P, Sultan M, Herwig R, Steinfath M, Balzereit D, Eppens B, Saran NG, Pletcher MT, South ST, Stetten G, Lehrach $H$, Reeves RH, Yaspo ML: Transcript level alterations reflect gene dosage effects across multiple tissues in a mouse model of down syndrome. Genome Res 2004, 14:1258-1267. 


\section{Pre-publication history}

The pre-publication history for this paper can be accessed here:

http://www.biomedcentral.com/1755-8794/3/40/prepub

doi:10.1186/1755-8794-3-40

Cite this article as: Costa et al:: Impairment of circulating endothelial

progenitors in Down syndrome. BMC Medical Genomics 2010 3:40.

Submit your next manuscript to BioMed Central and take full advantage of:

- Convenient online submission

- Thorough peer review

- No space constraints or color figure charges

- Immediate publication on acceptance

- Inclusion in PubMed, CAS, Scopus and Google Scholar

- Research which is freely available for redistribution

Submit your manuscript at 